\title{
Unexpected Recovery Risk and LGD Discount Rate Determination ${ }^{\#}$
}

\author{
Jiř̌i WITZANY*
}

\section{Introduction}

The main goal of this paper is to propose a consistent methodology for determination of the interest rate used for discounting of recovery cash flows of defaulted loans in order to estimate the Basle II Loss Given Default $(L G D)$ parameter that enters regulatory capital calculation (BCBS, 2006). Since the discount rate must reflect the risk or uncertainty of the recovery cash flow the study leads to a method of unexpected recovery (or $L G D$ ) risk modeling, a secondary byproduct important on its own from the practical and theoretical point of view. The task is also closely related to the concept of $L G D$ and $P D$ correlations that has been studied in a number of papers. It has been empirically shown by Altman et al. (2004), Gupton et al. (2000), Frye (2000a, 2000b, 2003), or Acharya et al. (2007) that there is not only a significant systemic variation of recovery rates but moreover a negative correlation between frequencies of default. The empirical studies are however in most cases based on market data on defaulted bonds where the recovery values are observed as market values of the bonds shortly after default. The discount rates implicitly used in such quotations are studied in Brady et al. (2006) and to the authors knowledge there is no other published study dealing with the discount rates from theoretical or empirical point view.

In the following subsections of the introduction we will precisely define the notions of recovery rate, loss given default, discount rate, and give an overview of the regulatory requirements and recommendations. The unexpected $L G D$ methodology and related discount rate calibration

\footnotetext{
\# The research has been supported by the Czech Science Foundation grant no. 402/09/0380 Correlation in Financial Risk Management and by the grant no. 402/09/0732 Market Risk and Financial Derivatives.

RNDr. Jiří Witzany, Ph.D. - assistant professor; Department of Banking and Insurance, Faculty of Finance and Accounting, University of Economics, Prague, W. Churchill Sq. 4, 13067 Prague 3, Czech Republic; <witzanyj@ vse.cz>.
} 
technique is outlined in Section 2. In Section 3 we perform a sensitivity study and calculate the discount rate based on a real data sample for the sake of illustration.

\subsection{Regulatory LGD and Recovery Discount Rates}

In order to estimate $L G D$ on non defaulted loan receivables banks firstly need to collect recovery data on loans defaulted in the past and measure efficiency of the process. According to the EP (2006), Title I, Article 4(26) banks should take into account all related costs as well as the discounting effects:

“'loss', for the purposes of Title V, Chapter 2, Section 3, means economic loss, including material discount effects, and material direct and indirect costs associated with collecting on the instrument."

Hence the discounted total recovery of a defaulted account based on known historical recovery cash flow including costs of the recovery process should be calculated using the standard present value formula

$$
R P V=\sum \frac{C_{t_{i}}}{(1+r)^{t_{i}}}
$$

where $R P V=$ recovery present value,

$C_{t} \quad=$ recovery cash flow at time $t$,

$r \quad=$ discount rate.

The cash flows are discounted to the time of default using an appropriate discount rate $r$. The recovery rate is then according to the regulation defined as the percentage rate $R R=R P V / E A D$ with respect to the exposure at default $E A D$. Finally we define $L G D=1-R R$.

The directive itself however does not give much guidance on how to set up the discount rates in practice. A little bit more could be found in the Basle Committee on Banking Supervision Paper "Guidance on Paragraph 468 of the Framework Document" (BCBS, 2005):

\section{"III. Principle for the discounting of recovery cash flows used in LGD estimation}

Most approaches to quantifying LGDs either implicitly or explicitly involve the discounting of streams of recoveries received after a facility 
goes into default in order to compare the net present value of recovery streams as of a default date with a measure of exposure at default.

Discount rates reflected in estimates of LGD must comply with the following principle.

\section{Principle 2}

For the estimation of LGDs, measures of recovery rates should reflect the costs (The concept of cost referred to here must be consistent with the concept of economic loss as described in paragraph 460 of the Revised Framework. This is not the accounting concept of cost) of holding defaulted assets over the workout period, including an appropriate risk premium.

When recovery streams are uncertain and involve risk that cannot be diversified away, net present value calculations must reflect the time value of money and a risk premium appropriate to the undiversifiable risk. In establishing appropriate risk premiums for the estimation of LGDs consistent with economic downturn conditions, the bank should focus on the uncertainties in recovery cash flows associated with defaults that arise during the economic downturn conditions identified under Principle 1. When there is no uncertainty in recovery streams (e.g., recoveries derived from cash collateral), net present value calculations need only reflect the time value of money, and a risk free discount rate is appropriate.

These measures of recovery rates can be computed in several ways, for example,

- by discounting the stream of recoveries and the stream of workout costs by a risk-adjusted discount rate which is the sum of the risk free rate and a spread appropriate for the risk of the recovery and cost cash flows,

- by converting the stream of recoveries and the stream of workout costs to certainty equivalent cash flows (A certainty-equivalent cash flow is defined as the cash payment required to make a risk averse investor indifferent between receiving the cash payment with certainty at the payment date and receiving an asset yielding an uncertain payout whose distribution at the payment date is 
equal to that of the uncertain cash flow) and discounting these by the risk free rate, or

- by a combination of adjustments to the discount rate and the stream of recoveries and the stream of workout costs that are consistent with this principle (A bank may use an "effective interest rate" in accordance with IAS 39 as the discount rate, but in that case should adjust the stream of net recoveries in a way that is consistent with this principle)."

One approach commonly used by banks and accepted by regulators is to discount the recovery cash flows with the interest rate of the defaulted loan account (or some sort of average on the defaulted pool) effective at the time of default. However such a discount rate may be based only on short-term interest rates while the duration of the cash flow to be discounted is generally measured in years and moreover the product credit margin may be generally quite independent on the economic risk of the recovery cash flow itself. The BCBS Guidance in fact requires adjusting the recovery cash flows in a way reflecting the uncertainty.

In every of the three approaches recommended by the guidance (riskadjusted discount rate, risk adjusted recovery cash flows discounted with the risk free rate, or risk-adjusted recovery cash flows discounted with an effective interest rate) a measure of recovery risk is needed. Once we find a consistent measure of the recovery $(L G D)$ risk and an estimate of the cost of risk we will be able to calculate the risk-adjusted discount rate.

\subsection{Downturn or Unexpected $L G D$}

Another reason for investigation of the $L G D$ risk, i.e. of the distribution of possible $L G D$ values, is regulator's requirement to produce $L G D$ estimates consistent with downturn conditions. According to EP (2006), Annex VII, Part 4, Article 74:

"Credit institutions shall use LGD estimates that are appropriate for an economic downturn if those are more conservative than the long-run average. To the extent a rating system is expected to deliver realized LGDs at a constant level by grade or pool over time, credit institutions shall make adjustments to their estimates of risk parameters by grade or pool to limit the capital impact of an economic downturn."

Moreover according to the EP (2006), Annex VII, Part 4, Article 80: 
"For the specific case of exposures already in default, the credit institution shall use the sum of its best estimate of expected loss for each exposure given current economic circumstances and exposure status and the possibility of additional unexpected losses during the recovery period."

An additional interpretation of downturn $L G D$ can be again found in the BCBS (2005) "Guidance on Paragraph 468 of the Framework Document" stressing the requirement to identify and incorporate into the $L G D$ estimates of adverse dependencies, if any, between default rates and recovery rates.

Thus if we are able to model the distribution of possible $L G D$ values driven by one or more systematic factor (possible common to probabilities of default) and if we set required downturn and unexpected risk probability levels (e.g. at 95\%) then we can also consistently set $L G D$ values for non defaulted as well as for defaulted but not yet recovered receivables.

\subsection{Market LGD Discount Rate}

The most straightforward approach for setting up a proper $L G D$ discount rate would be to observe it from market quotes provided there is an efficient market with bad loans. This approach requires not only a market value $M$ of a given $L G D$ homogenous portfolio with total exposure at default $E A D$ but also a qualified estimation of expected net recovery cash flows $C_{t}$ of the portfolio (for example on a monthly basis). Such an estimation could be obtained if part of the $L G D$ class is being efficiently recovered internally and another part is sold on the market. Given the estimated average cash flow $C_{t}$ and market price $P$, both as a percentage of $E A D$, to determine the implied discount rate we need to solve the equation

$$
P=\sum \frac{C_{t_{i}}}{(1+r)^{t_{i}}}
$$

where $P=$ market price of a bad loan.

The resulting discount rate $r$ reflects the current risk free interest rates, average maturity of the cash flow, and the risk as perceived by the market. Given the time-specific risk free rate $r_{f}$ (corresponding to the 
average cash flow duration) we can then calculate the risk premium $R P=r-r_{f}$ that should be used for general discount rate definition (defined as the actual risk free rate plus the risk premium) on defaulted receivables of the $L G D$ class. This approach has been taken for example by Brady et al. (2006) in an empirical study based on observed market prices and subsequent recoveries of bonds and banking loans. The study has identified some drivers of the discount rates and shown significant differences for various classes of defaulted assets.

\section{An Analytic LGD Discount Rate Estimation Approach}

\subsection{Market Price of Risk and LGD Economic Capital}

Since market data for defaulted (retail) receivables rarely exist we are going to propose an analytic estimation of the discount rate without having direct market prices of defaulted loans. Nevertheless we will still use financial markets to observe the cost of risk.

Investors generally require higher return for higher investment risk. In case of equity and similar assets the relationship is expressed by the Capital Asset Pricing Model (CAPM) relationship

$$
E\left(r_{i}\right)=r_{f}+\beta_{i}\left(E\left(r_{m}\right)-r_{f}\right)
$$

where $E\left(r_{i}\right)=$ expected return of asset $i$,

$r_{f} \quad=$ risk free rate,

$\beta_{i}=$ sensitivity of returns of the asset $i$ to market returns,

$E\left(r_{m}\right)=$ expected premium return of the market portfolio.

Thus the expected return of the asset $i$ depends just on its systematic risk, not on its specific or individual risk that can be diversified away in a large enough portfolio. This is an important fundamental fact we have to take into account estimating a theoretical $L G D$ discount rate.

Hence our approach is to estimate the systematic $L G D$ risk of a homogenous pool of receivables and set up the discount rate in line with the generally accepted $C A P M$. Nevertheless since it is difficult to measure sensitivity of a bad loan portfolio with respect to a market equity index we shall take another direction in fact fully consistent with the Basle II regulatory formula. We will estimate the economic capital reflecting systematic risk of an $L G D$ pool based on the Basle I probability level 
(99\%). We are using this probability level since the equity portfolio regulatory capital is defined as a constant $k$ (which can be assumed to be equal to 3 under normal conditions) times the 10 days Value at Risk at the $99 \%$ probability level. Given the long term volatility of a representative market risk index and the risk premium we may obtain a market implied cost of economic capital. Then we calculate the $L G D$ discount rate risk premium as a product of the relative economic capital and the implied cost of capital.

Specifically let $\sigma_{M}$ be the historical (or market implied) standard deviation of the market index annual return and $R P_{M}$ the corresponding risk premium over the risk-free interest rate. We assume that the standard deviation (volatility) in the one year horizon is based on a daily volatility $\sigma_{d, M}$ and the volatilities for other time horizons are recalculated using the square root of time rule. In particular $\sigma_{M}=\sqrt{252} \sigma_{d, M}$ or $\sigma_{d, M}=\sigma_{M} / \sqrt{252}$ provided there are 252 business days in a year, or the 10 business day volatility $\sigma_{10 d, M}=\sqrt{10} \sigma_{d, M}$ etc. The Basle I regulatory capital assigned to the risk of the market index portfolio can be estimated (with the coefficient $k=3$ and assuming normality) as a multiple of the portfolio value and the weight calculated as follows:

$$
\operatorname{Cap}_{B I}=3 N^{-1}(0.99) \frac{\sigma_{M}}{\sqrt{252}} \sqrt{10}
$$

where $\operatorname{Cap}_{B I}=$ Basel I capital requirement, $N^{1}=$ inverse standardized normal distribution,

$\sigma_{M}=$ stock market return annual volatility.

To estimate the market implied cost of economic (or risk) capital $(C R C)$ we need to solve the equation

$$
R P_{M}=C R C \cdot \text { Cap }_{B I}
$$

where $R P_{M}=$ market risk premium,

$C R C=$ cost of risk capital, i.e.

$$
C R C=\frac{R P_{M}}{N^{-1}(0.99) \cdot \sigma_{M} \sqrt{90 / 252}}
$$


A portfolio of bad loans in a non arbitrage market must provide in terms of expected return the risk-free return plus the same cost of risk multiplied by the economic risk of the portfolio. Since the returns of the bad loan portfolio (limited from above by the maximal possible cash receivable from the loans) are not normal we will rather estimate directly the $99 \%$ Value at Risk in the 10 day horizon consistently with the equity portfolio Basle I risk measure. However since bad loans are not usually in practice actively traded we will need to estimate the unexpected risk $\operatorname{Var}_{L G D}(T$ years, 99\%) in a recovery holding period of $T$ years (e.g. 2 or 3 years) and recalculate it to the 10 day period using the square root of time rule. Consequently

$$
\operatorname{VaR}_{L G D}(10 \text { days }, 99 \%)=\sqrt{\frac{10}{T \cdot 252}} \operatorname{VaR}_{L G D}(T \text { years }, 99 \%)
$$

where $\operatorname{Var}_{L G D}=$ full recovery period 99\% Value at Risk.

and so

$$
\operatorname{Cap}_{L G D}=\sqrt{\frac{90}{T \cdot 252}} \operatorname{VaR}_{L G D}(T \text { years }, 99 \%)
$$

where $\operatorname{Cap}_{L G D}=$ Recovery (LGD) risk capital.

Thus the $L G D$ risk premium and discount rate can be consistently defined as

$$
\begin{aligned}
& R P_{L G D}=C R C \cdot \text { Cap }_{L G D} \\
& r_{L G D}=r_{f}+R P_{L G D}
\end{aligned}
$$

$$
\text { where } \begin{aligned}
R P_{L G D} & =\text { recovery }(\mathrm{LGD}) \text { risk premium, } \\
r_{L G D} & =\text { recovery }(\mathrm{LGD}) \text { discount rate, } \\
r_{\mathrm{f}} & =\text { risk-free rate. }
\end{aligned}
$$

It remains to estimate the unexpected undiversifiable Loss Given Default $\left(\operatorname{Var}_{L G D}\right)$ parameter. A Basle II consistent method based on historical realized recovery data will be described in Section 2.4. However before we estimate the $L G D$ discount rate we already have to discount the historical recovery cash flows. This problem will be finally solved through an iterative procedure described in Section 2.5. A numerical example will be given in Section 3. 


\subsection{Basle II Unexpected Loss}

Basle II unexpected loss $U E L$ expressed as a percentage of exposure at default $E A D$ is in principle calculated as

$$
U E L=U D R \cdot L G D
$$

where $U E L=$ unexpected loss,

$U D R=$ unexpected default rate in a one year horizon on the $x=99.9 \%$ probability level,

$L G D=$ loss given default.

The calculation is done on account level but the UDR estimation reflects only the systematic (portfolio) risk not the account specific risk. Note that the $U E L$ formula does not take into account the unexpected risk of losses after default. It is rather obvious and has been confirmed by a number of studies that the additional unexpected risk is quite significant (see e.g. Altman et al., 2004). This partially explains the empirical fact that the Basle II capital requirement depends on the definition of default (see Witzany, 2009a and 2009b). Our goal is to extend the unexpected loss calculation beyond the UDR to capture the (systematic or portfolio) risk of unexpectedly high losses (low recoveries) on defaulted accounts. At the same time we would like to stay as close to the methodology of the regulatory formula as possible.

\subsection{Basle II Unexpected Default Rate}

The Basle II formula can be expressed as follows

$$
U D R=N\left(\frac{N^{-1}(P D)+\sqrt{\rho} \cdot N^{-1}(0,999)}{\sqrt{1-\rho}}\right)
$$

where $N=$ cumulative standardized normal distribution function, $\rho=$ correlation.

The correlation $\rho$ is set up by the regulator (15\% for mortgage loans, $4 \%$ for revolving loans, and somewhere between depending on $P D$ for other retail loans.)

It will be useful to recall the principle of the formula that was firstly discovered by Vasicek (1987). For a client $j$ let $T_{j}$ be the time to default on a client's debts. It is assumed that everyone will default once and as 
the time of the future event is unknown at present the time $T_{j}<\infty$ is a random variable. If $Q_{j}$ is the cumulative probability distribution of $T_{j}$ then it can be easily verified that the transformed variable $X_{j}=N^{-1}\left(Q_{j}\left(T_{j}\right)\right)$ is standardized normal (mean 0 , standard deviation 1 ). The advantage is that after the transformation we can take the assumption that the variables are multivariate normal and given their mutual correlation $\rho$ properties of normal variables can be used to obtain an analytic result. This approach is called the Gaussian copula model. The following one-factor model is used

$$
X_{j}=\sqrt{\rho} \cdot M+\sqrt{1-\rho} \cdot Z_{j}
$$

where $X_{j}=\operatorname{debtor} j$ risk factor,

$M=$ systematic factor,

$Z_{j}=$ debtor $j$ idiosyncratic factor.

$Z_{j}$ 's and $M$ have independent standard normal distributions. The one-year probability of default PD of the client $j$ can be then expressed as

$$
\begin{aligned}
& \operatorname{Pr}\left[T_{j} \leq 1\right]=\operatorname{Pr}\left[X_{j} \leq N^{-1}\left(Q_{j}(1)\right)\right]= \\
& =\operatorname{Pr}\left[\sqrt{\rho} \cdot M+\sqrt{1-\rho} \cdot Z_{j} \leq N^{-1}\left(Q_{j}(1)\right)\right]= \\
& =\operatorname{Pr}\left[Z_{j} \leq \frac{N^{-1}(Q(1))-\sqrt{\rho} M}{\sqrt{1-\rho}}\right]= \\
& =N\left(\frac{N^{-1}(Q(1))-\sqrt{\rho} M}{\sqrt{1-\rho}}\right)
\end{aligned}
$$

where $T_{j}=$ debtor $j$ time to default,

$Q_{j}=$ debtor $j$ time to default probability distribution.

The next step is to consider $M$ as the systematic driver of portfolio default rates. The model can be used for a simulation as follows: first generate randomly the value of $M$ from a standardized normal distribution and then independently generate all $Z_{j}$. If the portfolio is large enough then the simulated default rate on the portfolio level will be given by the formula above. If $M$ is large the simulated default rate will be low if $M$ is smaller then the portfolio default rate will be higher. For a given probability level $x$ the critical point of $M$ is given by the quantile $N^{-1}(x)$. When $M$ is replaced by $N^{-1}(x)$ and $Q(1)$ by the given average $P D$ we get exactly the regulatory formula (11). 


\subsection{Unexpected Loss Given Default}

This section will propose in a spirit similar to the Basle II approach an analytic formula for unexpected loss on a homogenous portfolio of defaulted receivables due to lower than expected recoveries.

Let $L R_{j}$ denote the percentage loss rate (i.e 1 - the recovery rate) on a defaulted receivable $j(j=1, \ldots, n)$. We also assume that the receivables are homogenous in terms of exposure. Since the portfolio is $L G D$ homogenous we can assume that the distribution of all $L R_{j}$ is the same with certain cumulative probability distribution function $Q . L R_{j}$ can be transformed as above to a standardized normal variable $Y_{j}=N^{-1}\left(Q\left(L R_{j}\right)\right)$. Standardized loss (recovery) rates are used for example by the KMV Loss Calc methodology (see Gupton, 2005 or Kim and Kim, 2006). Let us use again the following one systematic factor model for $Y_{j}$

$$
Y_{j}=\sqrt{\rho} \cdot V+\sqrt{1-\rho} \cdot W_{j}
$$

where $Y_{j}=$ standardized loss rate of receivable $j$,

$V=$ standardized normal systematic factor,

$W_{j}=$ independent standardized normal idiosyncratic factor.

A number of studies (see Altman et al., 2004) have confirmed not only that there is a correlation between the rates of default and the recovery rates but moreover that the two variables are driven by a common economic factor. This is in particular intuitive in the case of mortgages when a poor state of economy drives not only more clients to default but also reduces the value of the collaterals. The correlation could be estimated from historical data. However if there are only limited data (which is mostly our case) it makes sense to use the same regulatory correlation coefficients (with an average taken for the Basle II class of "other receivables" where the correlation coefficient depends on PD). For a given probability level $x$ (e.g. 99\%) similarly as above the losses on a portfolio level are generated just by the value of $V$ as the independent values $W_{j}$ diversify away for a large $n$. The unexpected portfolio loss rate takes place if $V$ is at the high level expressed by the quantile $N^{-1}(x)$. Consequently the unexpected loss rate is

$$
U L R(x)=E\left[Q^{-1}\left(N\left(\sqrt{\rho} N^{-1}(x)+\sqrt{1-\rho} \cdot W\right)\right]\right.
$$

where $x=$ probability level, 
with expectation is taken over all values of a standardized normal variable $W$. The expected value can be calculated numerically using the standardized normal density of $W$, i.e.

$$
U L R(x)=\int_{-\infty}^{+\infty} Q^{-1}\left(N\left(\sqrt{\rho} N^{-1}(x)+\sqrt{1-\rho} \cdot w\right) \frac{1}{2 \pi} e^{-\frac{w^{2}}{2}} d w\right.
$$

To calculate the $L G D$ Value at Risk we need to subtract the mean loss rate and divide it by the initial value equal to one minus the expected loss, i.e.

$$
\operatorname{VaR}_{L G D}=\frac{U L R(0.99)-E\left[Q^{-1}(Y)\right]}{1-E\left[Q^{-1}(Y)\right]}
$$

The mean loss rate, i.e. $E\left[Q^{-1}(Y)\right]=L G D$, is either entered as a parameter into the calibration or can be obtained by integration over the standard normal density of $Y$. Note that Value at Risk is estimated at the horizon $T$ of the recovery process in which the final loss value is to be determined. Hence we have obtained in fact $\operatorname{VaR}_{L G D}(T$ years, $99 \%)$.

Compared to the Vasicek formula we have not unfortunately eliminated the loss rate account level probability distribution function $Q$. Note that there is one difference: while in the case of default rates we model on an account level a variable taking only two values $(0-$ no default and 1 - default) in the case of $L G D$ we model a variable taking in general any value in the range $[0 ; 1]$ and so the distribution $Q$ does matter even at the portfolio level. Given the correlation and probability level $x$ we still need to model the $L G D$ distribution $Q$.

Empirical studies (see Gupton et al., 2005 or Schuermann, 2004) show that the beta distribution is relatively appropriate for $L G D$ modeling. The beta distribution probability density function with minimum 0 , maximum 1 , and parameters $\alpha, \beta$ is

$$
f_{\text {beta }}(x, \alpha, \beta)=\frac{\Gamma(\alpha+\beta)}{\Gamma(\alpha) \Gamma(\beta)} x^{\alpha-1}(1-x)^{\beta-1}
$$

where $\alpha=$ Alpha distribution parameter,

$\beta=$ Beta distribution parameter, 
and where $\Gamma(\alpha)=\int_{0}^{\infty} x^{\alpha-1} e^{-x} d x$ is the standard gamma function. The parameters $\alpha, \beta$ can be calculated from the mean $\mu$ and standard deviation $\sigma$ of the modeled variable

$$
\begin{aligned}
& \alpha=\mu\left(\frac{\mu(1-\mu)}{\sigma^{2}}-1\right), \\
& \beta=(1-\mu)\left(\frac{\mu(1-\mu)}{\sigma^{2}}-1\right) .
\end{aligned}
$$

where $\mu=$ mean,

$$
\sigma=\text { standard deviation. }
$$

To calibrate the distribution function we can use either the mean and standard deviation from historical $L G D$ data on the product (we assume that it is possible to measure $L G D$ on account level) or, if not available, public data which are unfortunately as far as we know available only for public corporate bonds and bank loans (see e.g. Altman et al., 2004).

Figure 1 shows how an account level distribution (on the left hand side) is transformed by (16) to the portfolio $L G D$ distribution (on the right hand side) with the indicated parameters. 
Witzany, J.: Unexpected Recovery Risk and LGD Discount Rate Determination.

Fig. 1: Account level beta distribution $(\mu=20 \%$ and $\sigma=30 \%)$ and its transformation into a portfolio distribution $(\rho=10 \%)$
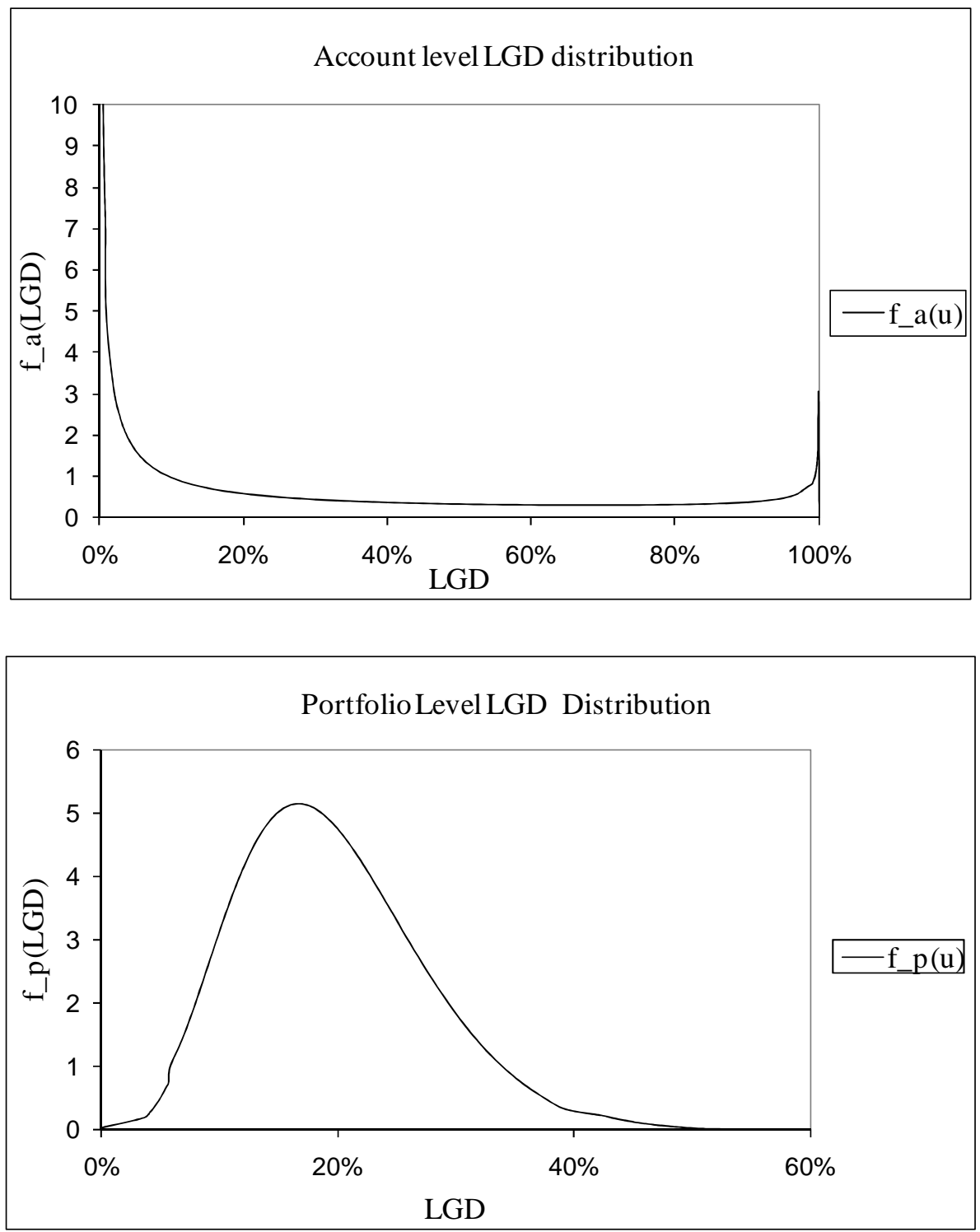

Source: Own calculations

Empirical experience often shows a bimodal distribution of observed account level $L G D$ values. In this case it may be more appropriate to use a mix of two beta distribution with the density function defined as follows 


$$
\begin{aligned}
& f_{\text {bim }}\left(x, \alpha_{L}, \beta_{L}, \alpha_{H}, \beta_{H}\right)= \\
& \quad=p_{L} \cdot f_{\text {beta }}\left(x, \alpha_{L}, \beta_{L}\right)+\left(1-p_{L}\right) \cdot f_{\text {beta }}\left(x, \alpha_{H}, \beta_{H}\right)
\end{aligned}
$$

where we may separately model low and high $L G D$ values that are observed with probabilities $p_{L}$ and $1-p_{L}$.

While the account level $L G D$ distribution can be relatively easily calibrated based on historical data the biggest challenge is to estimate the $L G D$ correlation $\rho$ that requires a longer time series. Section 3 indeed shows that the unexpected portfolio $L G D$ risk is sensitive to the correlation parameter. Given a set of observed loss rates from a single time period we cannot estimate the parameter $\rho$ since the unknown systematic factor $V$ is supposed to be fixed while the idiosyncratic factor $W_{j}$ varies. Hence we need to observe $L G D$ s from different time periods and calibrate $\rho, \mu, \sigma$ (or other parameters in case of the bimodal distribution) minimizing e.g. the sum of least square errors or maximizing the likelihood function given by (15). Specifically given the (unknown) parameters $\rho, \mu, \sigma$ and a time $t$ observed portfolio loss rate $L R_{t}$ find the corresponding systematic factor value $V_{t}$ so that $L R=U L R\left(V_{t}\right)$ according to (15). Then $\ln \phi\left(V_{t}\right) / \frac{\partial}{\partial V} U L R\left(V_{t}\right)$ (where $\phi$ is the standardized normal density) is the contribution to log likelihood function being maximized with respect to $\rho, \mu, \sigma$ (see also Frye, 2000b). An alternative practical but quite simplistic approach is to use the same correlation regulatory values as for $P D$.

\subsection{An Iterative Calculation of the LGD discount rate}

Given a homogenous portfolio of defaulted loans with total nominal outstanding $E A D$ and a fair estimation of $\operatorname{Var}_{L G D}$ we can calculate according to Section 2.1 the $L G D$ economic capital and the corresponding risk premium $R P_{L G D}$ that should be added to a risk free rate for discounting of realized or expected recovery cash flows.

The definition of the discount factor is in fact circular and so we have to start first with an estimation of the $L G D$ risk premium $R P_{1}$, for example $2 \%$, and use it together with the actual risk free rate $r_{\mathrm{f}}$ for discounting historical recoveries to calibrate the beta distribution and 
obtain $\operatorname{Var}_{L G D}$ as above. The formula (9) then gives a new value of $R P_{2}$ of the risk premium which generally differs from $R P_{1}$. The idea is to iterate the process obtaining $R P_{n}=F\left(R P_{n-1}\right)$ from $R P_{n-1}$ until the values converge with a given precision to $R P=\lim _{\mathrm{n} \rightarrow \infty} R P_{n}$.. In practice we stop when $\left|R P_{n}-R P_{n-1}\right|$ is less than a given precision parameter, e.g. $\varepsilon=0.1 \%$.

Regarding convergence note that discounted values, mean and standard deviation are continuous functions of the discount rate and hence of the risk premium. If the initial risk premium is infinite (very large) than all discounted recoveries are equal (almost) to zero, $L G D=100 \%$ and there is no $L G D$ risk, i.e. $\operatorname{Var}_{L G D}=0$ and $R P_{L G D}=0$, in other words $\lim _{x \rightarrow \infty} F(x)=0$. Obviously $F(0)>0$ for a nontrivial dataset and moreover the function is decreasing provided that the recovery cash flows are regularly distributed, hence larger discount rates reduce the $V a R_{L G D}$ and the updated risk premium. Under those assumptions the solution of the equation $F(x)=x$ analytically exists, is unique, and can be obtained by the described iterative process. An example in Section 3 shows that less than 5 iterations are quite sufficient.

\subsection{Simplified LGD economic capital calculation}

According to some empirical studies the beta distribution does not necessarily faithfully model the distribution of recovery rates (see Schuermann, 2004). The recovery rates can be for some products bimodal - the recovery rates are either rather low or rather high as already mentioned in Section 2.4. This is not surprising in particular in the case of collateralized products like mortgages. The collateral is either successfully sold and the defaulted receivables more or less paid back or there is an unexpected problem with the receivable and the recovery is low. Taking a simplified approach we can assume that there are only two possible recovery rates (and $L G D$ ) values: 0 and 1 . Then (looking backward or into the future) we can distinguish two types of defaults: full-loss-defaults and zero-loss-defaults. As there is no loss on zero-lossdefaults those can be forgotten and all we need to model are the full-loss defaults. The probability of a full-loss-default is $P D \cdot L G D$ as $L G D$ is in this case just the probability of full loss conditioned by a default and $P D$ is the probability of default. The loss conditioned by a full-loss-default is certainly $100 \%$, so unexpected default rate equals directly to the 
unexpected loss in this case. The event of a full-loss-default can be modeled using the Gaussian Copula Vasicek model:

$$
U E L_{2}=N\left(\frac{N^{-1}(P D \cdot L G D)+\sqrt{\rho} \cdot N^{-1}(0.99)}{\sqrt{1-\rho}}\right)
$$

where $P D=$ probability of default.

$U E L_{2}$ captures both the unexpected default rate and $L G D$ given a systematic correlation $\rho$. To get $L G D$ contribution we need to deduct the unexpected loss capturing only the unexpected default rate:

$$
U E L_{1}=N\left(\frac{N^{-1}(P D)+\sqrt{\rho} \cdot N^{-1}(0.99)}{\sqrt{1-\rho}}\right) \cdot L G D
$$

Unexpected loss is measured in the two formulas (21) and (22) as a percentage of the total portfolio outstanding before default. Hence the 99\% unexpected $L G D$ economic capital as a percentage of the initial value $1-L G D$ can be expressed as

$$
\operatorname{VaR}_{L G D}=\frac{U L G D-L G D}{1-L G D}
$$

where $U L G D=\frac{U E L_{2}-U E L_{1}}{P D}$.

One disturbing empirical issue is dependence of the $L G D$ economic capital on $P D$ (the economic capital is allocated to a portfolio of already defaulted receivables). We propose to use simply $P D=1$, i.e.

$$
V a R_{L G D}=\frac{N\left(\frac{N^{-1}(L G D)+\sqrt{\rho} \cdot N^{-1}(0,99)}{\sqrt{1-\rho}}\right)-L G D}{1-L G D}
$$

The big advantage of this approach is that we do not need to calibrate and numerically integrate any Beta distribution. On the other hand we still need to perform an iterative process since $L G D$ does depend on the discount rate. A disadvantage of the simplified approach is that it is rather conservative as confirmed by the empirical comparison in the next section. 


\section{An Empirical Study}

\subsection{Sensitivity of the unexpected LGD to the input parameters}

We have tested sensitivity of $V a R_{L G D}$ given by (17) in the case of a simple beta distribution calibrated to input parameters $\rho, \mu, \sigma$. The unexpected loss rate is evaluated through numerical integration of beta inverse function on the probability level $x=99 \%$.

Fig. 2: $\quad V a R_{L G D}$ dependence on overall portfolio correlation for the values

1. $\mu=20 \%, \sigma=15 \%, 2 . \mu=40 \%, \sigma=20 \%, 3 . \mu=60 \%, \sigma=30 \%$

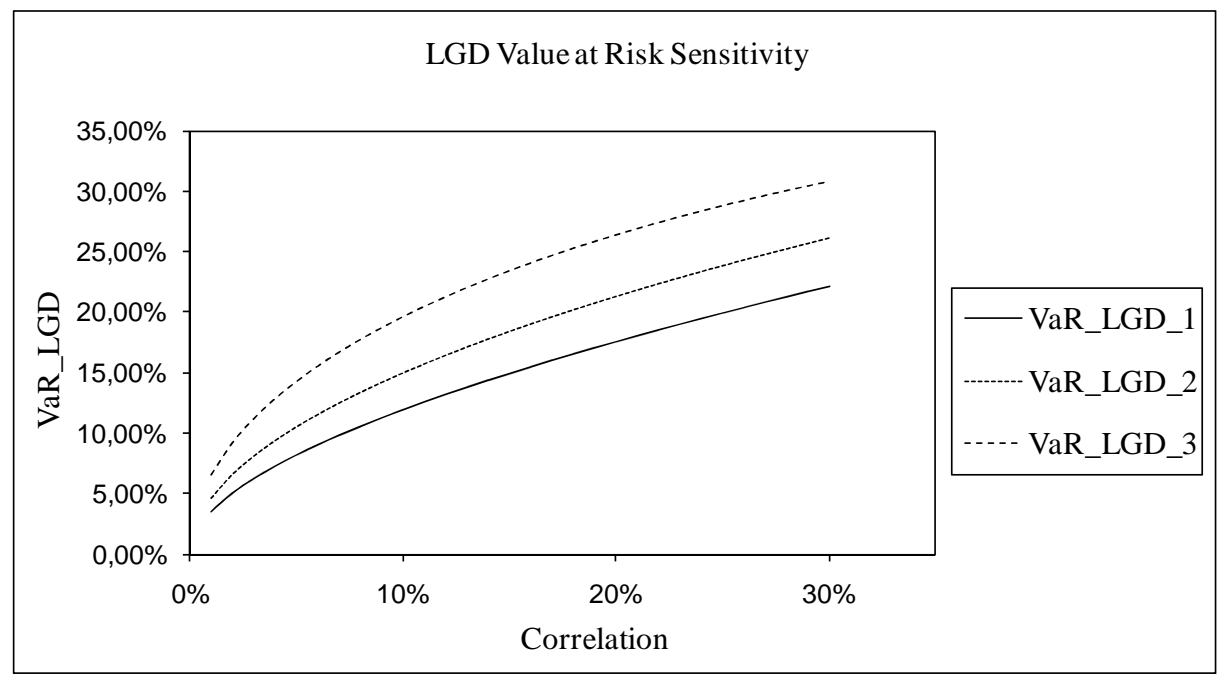

Source: Own calculations

Figure 2 shows an obvious positive monotone dependency of $L G D$ Value at Risk on overall portfolio correlation factor $\rho$. More importantly, it is evident that the behavior is relatively regular for different $L G D$ mean and standard deviation values.

In what follows, let us fix the correlation parameter $\rho$ at $10 \%$. 
Fig. 3: $\quad V a R_{L G D}$ dependence on mean LGD (10\% portfolio correlation

$$
\begin{aligned}
\rho), \text { 1. } \sigma=5 \%, 2 . & =15 \%, 3 . \sigma=25 \%, \text { and 4. estimation } \\
& \text { according to (24) }
\end{aligned}
$$

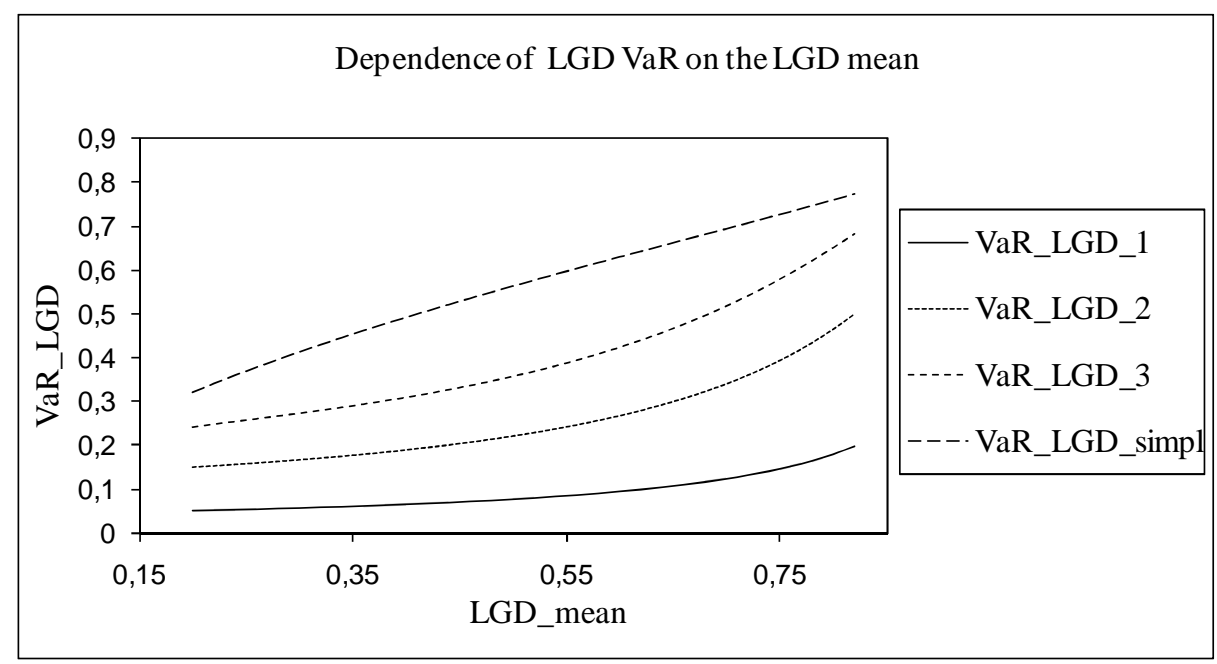

Source: Own calculations

The figure shows that $V a R_{L G D}$ does not depend significantly on $L G D$ mean as long as it stays below $65 \%$. Larger values of $V a R_{L G D}$ for large $L G D$ mean are caused rather by the fact that the potential losses are measured with respect to very small expected recovery rate. The $V a R_{L G D}$ value however does depend significantly on the $L G D$ standard deviation and is particularly high in the simplified approach when the standard deviation is effectively maximized as the model admits only two recovery values $0 \%$ or $100 \%$. Hence even though the simplified formula (24) appears to be attractive the cost in terms of overestimated risk may be quite high.

\subsection{Discount rate calculation example}

The goal of this subsection is to illustrate the $L G D$ discount rate estimation method on real data. We do not want to provide a general $L G D$ discount rate estimation but only to give a practical example indicating where the real life discount rate value obtained using the method might be. We will use a sample of recovery history data on unsecured retail loans from the period 2002-2007 obtained from a large retail bank. We 
have selected only the accounts (counting 170) with completed recovery history of length at least 36 months. We will use a historical average risk free interest rate $r_{0}=2.8 \%$ (1Y Pribor 2002-2007) although in practice we should use rather the historical term structure of risk free interest rates according to the time of default and time from which the cash flow is discounted.

To estimate the risk premium according to Section 2.5 we firstly need to determine the cost of risk capital $C R C$ according to Section 2.1. The value is calculated from the market risk premium $R P_{M}$ and market return volatility $\sigma_{M}$, or in fact from the Sharpe ratio $R P_{M} / \sigma_{M}$. There is a number of studies on the subject (see e.g. Officer and Bishop, 2009). We will use the average return and standard deviation of the PX index 1997$2007\left(r_{M}=12.9 \%\right.$ and $\left.\sigma_{M}=23.8 \%\right)$ and the average one year (Pribor) risk free rate in the same period $\left(r_{f}=5.8 \%\right)$. The domestic market based cost of risk capital according to (6) then is $C R C=21.5 \%$.

Next we need to start the iterative procedure described in Section 2.5. We will use the risk free base interest rate $r_{0}=2.8 \%$ and start with an expert estimation of the $L G D$ risk premium $R P_{1}=4 \%$. The interest rate $r=r_{0}+R P_{1}=6.8 \%$ is then used to discount the given recovery cash flow according to (1) and calculate the sample $L G D$ mean $\mu=51.64 \%$ and standard deviation $\sigma=24.97 \%$. To calculate the portfolio unexpected $L G D$ according to (16) we yet need to determine the $L G D$ correlation $\rho$. Its estimation from a given dataset using different methods should be a subject of a subsequent study. At this point we use the approximate regulatory value $\rho=10 \%$. The unexpected loss is then $U L R=66.34 \%$ and the $L G D$ Value at Risk $V a R_{L G D}=34.82 \%$. To calculate the updated risk premium $R P_{2}=2.93 \%$ according to (9) we have used the cash flow weighted average time of recovery $T=3.06$. The process is then repeated until the difference between $R P_{n}$ and $R P_{n-1}$ is less than a given error, e.g. $\varepsilon=0.01 \%$. As shown in Table 1 the iteration is very fast and we get $R P=R P_{3}=2.92 \%$ and the final discount rate $r=5.72 \%$ only after three rounds of the iteration. 
Tab. 1: An iterative calculation of the LGD risk premium

\begin{tabular}{|c|c|c|c|c|c|c|c|c|}
\hline Iter. & $\begin{array}{c}\text { Initial } \\
\text { RP }\end{array}$ & $\mathbf{r}$ & $\boldsymbol{\mu}$ & $\boldsymbol{\sigma}$ & $\boldsymbol{\rho}$ & $\mathbf{U L R}$ & $\mathbf{V a R}_{\mathbf{L G D}}$ & $\begin{array}{c}\text { New } \\
\text { RP }\end{array}$ \\
\hline $\mathbf{1}$ & $4.00 \%$ & $6.80 \%$ & $51.64 \%$ & $24.97 \%$ & $10.00 \%$ & $66.34 \%$ & $34.82 \%$ & $2.93 \%$ \\
\hline $\mathbf{2}$ & $2.93 \%$ & $5.73 \%$ & $52.68 \%$ & $25.29 \%$ & $10.00 \%$ & $65.60 \%$ & $34.70 \%$ & $2.92 \%$ \\
\hline $\mathbf{3}$ & $2.92 \%$ & $5.72 \%$ & $52.69 \%$ & $25.29 \%$ & $10.00 \%$ & $65.59 \%$ & $34.70 \%$ & $2.92 \%$ \\
\hline
\end{tabular}

\section{Conclusion}

We have proposed a CAPM consistent iterative method for $L G D$ discount rate determination. It allows to start with a collection of historical recovery data and find through a quick empirical iteration the appropriate discount rate as well as to obtain stressed $L G D$ values. The approach can be also used to get a credit portfolio economic capital estimation incorporating the $L G D$ unexpected risk. $L G D$ correlation has been identified as one of the most important parameters of the calculation. The parameter is difficult to estimate. We have proposed to use the Basle II regulatory value in the simplest approach and at the same time outlined a maximum likelihood estimation procedure. This and other alternative calibration methods related to the issue of correlation should be further investigated in a subsequent paper.

\section{References}

[1] Acharya, V. - Bharath, S. - Srinivasan, A. (2007): Does Industrywide Distress Affect Defaulted Firms? Evidence from Creditor Recoveries. Journal of Financial Economics vol. 85, no.3, pp. 787821.

[2] Altman, E. - Resti, A. - Sironi, A. (2004): Default Recovery Rates in Credit Risk Modelling: A Review of the Literature and Empirical Evidence. Economic Notes by Banca dei Paschi di Siena SpA, 2004, vol. 33, no. 2, pp. 183-208.

[3] BCBS (2005): Guidance on Paragraph 468 of the Framework Document. [on-line], Basel, Bank for International Settlements, Basel Committee on Banking Supervision, c2005, [cit $27^{\text {th }}$ March, 2009], <http://www.bis.org/publ/bcbs115.pdf>. 
Witzany, J.: Unexpected Recovery Risk and LGD Discount Rate Determination.

[4] BCBS (2006): International Convergence of Capital Measurement and Capital Standards, A Revised Framework - Comprehensive Version. [on-line], Basel, Bank for International Settlements, Basel Committee on Banking Supervision, c2006, [cit 27 ${ }^{\text {th }}$ March, 2009], $<$ http://www.bis.org/publ/bcbs128.pdf $>$.

[5] Brady, B. - Chang, P. - Miu, P. - Ozdemir, B. - Schwartz, D. (2006): Discount Rate for Workout Recoveries: An Empirical Study. [on-line], Washington, D. C., Federal Deposit Insurance Company, c2006, [cit. 27 ${ }^{\text {th }}$ March, 2009],

<http://www.fdic.gov/bank/analytical/CFR/2006/sept/MiuP.pdf>.

[6] EP (2006): Directive 2006/48/EC of the European Parliament and the Council of 14 June 2006 relating to the taking up and pursuit of the business of credit institutions (recast). [on-line], Official Journal of the European Union, 30 ${ }^{\text {th }}$ June, 2006, [cit. 27 ${ }^{\text {th }}$ March, 2009], <http://eur-lex.europa.eu/LexUriServ/LexUriServ.do?uri=OJ:L:2006 :177:0001:0200:EN:PDF>.

[7] Frye, J. (2000a): Collateral Damage. Risk, vol.13, no. 4, pp. 91-94.

[8] Frye, J. (2000b): Depressing Recoveries. Risk, vol. 13, no. 11, pp. 106-111.

[9] Frye, J. (2003): A False Sense of Security. Risk, vol. 16, no. 8, pp. 63-67.

[10] Gupton, G. M. - Gates, D. - Carty, L. (2000): Bank Loan Losses Given Default. Moody's Global Credit Research, Special Comment.

[11] Gupton, G. M. (2005): Advancing Loss Given Default Prediction Models: How the Quiet Have Quickened. Economic Notes by Banca dei Paschi di Siena SpA, 2005, vol. 34, no. 2, pp. 185-230.

[12] Kim, J. - Kim, H. (2006): Loss Given Default Modelling under the Asymptotic Single Risk Factor Assumption. [on-line], Munich, Munich Personal RePEc Archive Paper no. 860, c2007, [cit. $27^{\text {th }}$ March, 2009],

<http://mpra.ub.uni-muenchen.de/860/1/MPRA_paper_860.pdf > .

[13] Officer, B. - Bishop, S. (2009): Market Risk Premium. A Review Paper Prepared for Energy Networks Association. [on-line], Melbourne, Value Adviser Associates, c2009, [cit. 27 ${ }^{\text {th }}$ March, 2009], $<$ http://www.acc.gov.au/content/item.phtml?itemId=897313\&nodeI $\mathrm{d}=3094 \mathrm{~b} 9 \mathrm{~b} 4 \mathrm{f} 42503 \mathrm{~b} 7151 \mathrm{a} 5 \mathrm{c} 678 \mathrm{a} 8 \mathrm{~d} 61 \mathrm{e} 7 \& \mathrm{fn}=\mathrm{SSD} 2.29 \% 20 \mathrm{Bishop}$ $\% 20$ and\%20Officer\%20Report\%20January\%202009.pdf $>$. 
[14] Schuermann, T. (2004): What Do We Know About Loss Given Default. Credit Risk Models and Management, London, Risk Books, 2004.

[15] Vasicek, O. (1987): Probability of Loss on a Loan Portfolio. [on-line], San Francisco, KMV, c1987, [cit. 27 ${ }^{\text {th }}$ March, 2009], <http://www.moodyskmv.com/research/files/wp/Probability_of_Loss _on_Loan_Portfolio.pdf>.

[16] Witzany, J. (2009a): Basle II Capital Requirements Sensitivity to the Definition of Default. ICFAI University Journal of Financial Risk Management, 2009, vol. 6, no. 1, pp. 55-75.

[17] Witzany, J. (2009b): Loss, Default, and Loss Given Default Modeling. [on-line], Prague, Charles University, Institute of Economic Studies, Working Paper no. 9/2009, [cit. 27 ${ }^{\text {th }}$ March, 2009], <ies.fsv.cuni.cz/default/file/download/id/10089> 


\title{
Unexpected Recovery Risk and LGD Discount Rate Determination
}

Jiři WITZANY

\begin{abstract}
The Basle II parameter called Loss Given Default ( $L G D$ ) aims to estimate the expected losses on not yet defaulted accounts in the case of default. Banks firstly need to collect historical recovery data, discount the recovery income and cost cash flow to the time of default, and calculate historical recovery rates and LGDs. One of the puzzling tasks is to determine an appropriate discount rate which is very vaguely characterized by the regulation. This paper proposes a market consistent methodology for the $L G D$ discount rate determination based on estimation of the systematic, i.e. undiversifiable, recovery risk and a cost of the risk.
\end{abstract}

Key words: Credit risk; Recovery rate; Loss given default; Discount rate; Regulatory capital.

JEL classification: G21, G28, C14. 